\title{
Application of the Upper-Bench CD Method in Super Large-Span and Shallow Tunnel: A Case Study of Letuan Tunnel
}

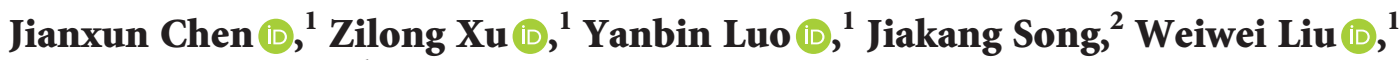 \\ and Fangfang Dong ${ }^{1}$ \\ ${ }^{1}$ School of Highway, Chang'an University, Xi'an 710064, China \\ ${ }^{2}$ Shandong High Speed Construction Management Group Limited Company, Shandong 250098, China \\ Correspondence should be addressed to Zilong Xu; xzilong1991@163.com
}

Received 28 April 2020; Revised 2 June 2020; Accepted 30 June 2020; Published 23 July 2020

Academic Editor: Chunshun Zhang

Copyright ( $(2020$ Jianxun Chen et al. This is an open access article distributed under the Creative Commons Attribution License, which permits unrestricted use, distribution, and reproduction in any medium, provided the original work is properly cited.

In order to keep pace with fast urbanization and explosive growth of highway traffic volume in China, more and more super large-span tunnels are constructed or will be constructed in the coming years. It is of great significance to employ a suitable construction method for ensuring construction safety when tunnelling in a complicated geological environment. Based on the reconstruction and expansion project of Binlai in China, this paper aims at studying deformation behaviors and mechanical properties of super large-span and shallow tunnel constructed using the upper-bench CD method. The study results showed that the crown settlement of the pilot tunnel was larger than that of the rear guide tunnel, and the deformation of rock mass tended to be stable after 60 days of excavation. The structural stress changed greatly in the construction stage, the stress distribution of steel rib was mainly under compression, and the maximum compressive stress of shotcrete appeared at the tunnel vault. The supporting structure was always kept in a safe state, and its safety factor was higher than 1.5. However, the upper-bench CD method has poor performance in controlling surface subsidence and horizontal convergence. The study of this paper provides a new construction method and useful reference for similar super large-span tunnels.

\section{Introduction}

With the rapid development of national economy and the urgent demand of highway transportation development in China, existing single-hole two-lane highway tunnels can no longer satisfy the transportation needs, resulting in the emergence of double-hole eight-lane tunnels in many new or extension projects, such as Qingxi Tunnel, China Hanjialing Tunnel, and Longtoushan Tunnel [1-3]. The excavation spans of double-hole eight-lane tunnels are generally larger than $18 \mathrm{~m}$, which are defined as super large-span tunnels. The single-hole four-lane tunnel is characterized by large excavation area, large span, and low flatness, which is significantly different with medium- and small-span tunnels. A series of construction problems, such as large deformation of rock mass, structure failure of supporting structure, or even collapse, often occur during the construction of super largespan tunnels. For tunnel construction, sequential excavation methods are usually used to reduce the excavation span and control the deformation of rock mass, such as the both-side drift method, CD method, and CRD method.

In recent years, with the improvement of tunnel construction standard, more attention has been paid to the reasonable construction method of super large-span tunnels in complex geological environment [4-8]. No et al. [9], Sadaghiani and Dadizadeh [10], Sharifzadeh et al. [11], Bao et al. [12], Boonyarak and Ng [13], and Yoo and Choi [14] studied the influence of different excavation methods and excavation sequences on the deformation, structural stress, and construction safety of tunnels through field tests, centrifugal tests, and numerical simulations. Based on the deterioration of rock mass, the HRM method was used to analyze the influence of load and time on the supporting structure [15-18]. Luo et al. [19] and Li [20] optimized the support parameters by analyzing the deformation of rock mass and the mechanical characteristics of support. In order to ensure structural quality and construction safety, the 3D convergence measurement, observation, and RDM methods 
were used to monitor the displacement and structural stress of rock mass [21-24].

The upper-bench CD method is an improved type of traditional CD method, and its construction sequence is shown in Figure 1. Compared with traditional CD method, the upper-bench CD method has the advantage of shortening cycle time, which greatly improves construction efficiency and saves the construction cost by reducing temporary support [25]. However, it is still unclear for the mechanical properties and structural safety of super largespan tunnels constructed by the upper-bench CD method in the construction process. Therefore, it is necessary to study deformation behaviors and mechanical properties of super large-span tunnels and explore the application scope of the upper-bench CD method based on the Letuan Tunnel in the reconstruction and expansion project of Binlai in China. The deformation data on rock mass and structural stress of supporting structures were obtained through field tests, and the mechanical properties and safety analyses of the supporting structures are performed by numerical simulation. This study can provide reference for similar engineering construction of super large-span tunnels.

\section{Engineering Survey and Monitoring Scheme}

2.1. Engineering Survey. Letuan Tunnel is located in Laiwu District, Jinan City, Shandong Province, China. The Letuan Tunnel's total length is $2010 \mathrm{~m}$, and its maximum depth is $107 \mathrm{~m}$. The maximum excavation width and height of Letuan Tunnel are 21.5 and $14.3 \mathrm{~m}$, respectively. The tunnel site is a low hilly landform with a well-developed surface vegetation. The rock mass are mainly strong and moderately weathered limestone and marl. According to the code for design of highway tunnels in China, it can be determined from the excavation span and surrounding rock level that a super long-span tunnel is a shallow tunnel when its buried depth is less than or equal to $38.2 \mathrm{~m}$. The face and field constructions are shown in Figures 2 and 3, and the longitudinal section of tunnel is shown in Figure 4.

The supporting structure is composed of composite lining in which bolt, steel arch, and wet shotcrete are the primary support, and reinforced concrete is the secondary lining. The steel frame is constructed with $\mathrm{H} 200$ steel with a $60 \mathrm{~cm}$ longitudinal spacing, the shotcrete is $\mathrm{C} 25$, and the secondary lining is a $70 \mathrm{~cm}$ thick C30 concrete.

2.2. Monitoring Scheme. The field test includes deformation and stress tests. The deformation test includes crown settlement and horizontal convergence. The stress test includes contact pressure and structural stress. Stress monitoring is carried out by a steel string sensor with high sensitivity and good stability in the field test. The main instruments used are Topcon ES-101 total station and MWT-2172 vibrating string acquisition instrument. In order to ensure the real and effective test data, the initial frequency calibration is carried out in the laboratory and on-site to ensure the consistency of the two data. The test items and frequencies are listed in Table 1. A total of 84 steel string sensors were embedded in the ZK105 + 952 section, and the specific measuring points are shown in Figure 5.

\section{Results and Discussion}

3.1. Deformation Monitoring. As shown in the crown settlement temporal curve in Figure 6, the crown settlement of the pilot tunnel is larger than that of the rear guide tunnel, and the ratio of the stable settlement deformation of the latter guide tunnel to that of the pilot tunnel is approximately $40 \%$. Therefore, attention should be paid to reducing the excavation amount caused by the reserved deformation of the rear guide tunnel during construction. The variation of crown settlement can be divided into three stages, namely, rapid growth, slow growth, and basic stable stages. The deformation of enclosed rock mass with initial support is mainly internal displacement, which can be used as a secondary lining.

The temporal curve of horizontal convergence shown in Figure 7 shows that the law of horizontal convergence is consistent with the law of crown settlement and deformation, which can be divided into three stages and finally reaches a stable state. Given that blasting vibration has a considerable influence on temporary support, the measuring lines (E-F and $\mathrm{H}-\mathrm{I}$ ) of the pilot tunnel after excavation are not monitored. According to the monitoring data, the deformation of the rock mass tends to be stable when the monitoring section is $120 \mathrm{~m}$ (60 day) away from the excavation face, and the deformation tends to be stable when the inverted arch surface is $40 \mathrm{~m}$ (20 days) away from the excavation face, which is consistent with the law proposed in [26]. Rock mass deformation is closely related to the distance $(L)$ from the monitoring section to the excavation face and the tunnel diameter $(D)$. Convergence displacement is exponentially related to $L / D$ and is generally stable after the $L /$ $D$ value reaches $2-3$.

3.2. Force Testing. Through the stress measurement of the support structure, its stress state can be mastered, its stability and safety can be judged, and then its rationality can be checked. In order to facilitate the safety analysis of the tunnel, the most unfavorable state of each measuring point of the tunnel in the whole construction stage is counted and the distribution diagram is obtained.

3.2.1. Shotcrete Stress Analysis. The stress of shotcrete in Figure 8 indicates that the stress of shotcrete has a considerable influence on the construction process. The tensile phenomenon of some measuring points exceeds the ultimate tensile strength $(1.5 \mathrm{MPa})$ of shotcrete $(\mathrm{C} 25)$, which leads to cracking, peeling, and even shedding of the concrete surface. Therefore, the cracking resistance of shotcrete should be strengthened in the initial support design and construction. It can be seen from Figure 8 that the stress of shotcrete is asymmetric. The reason is that the right side is the leading side, the rock mass has large deformation, and the rock is easy to fall off and slide when the tunnel is shallow. 


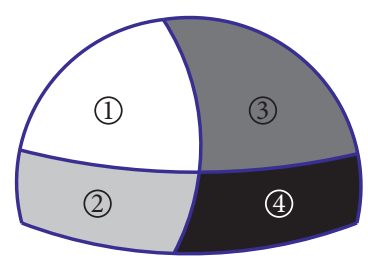

(a)

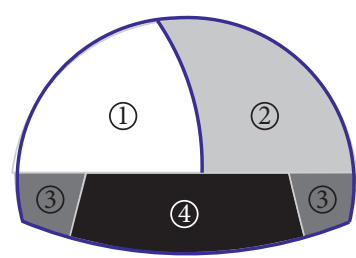

(b)

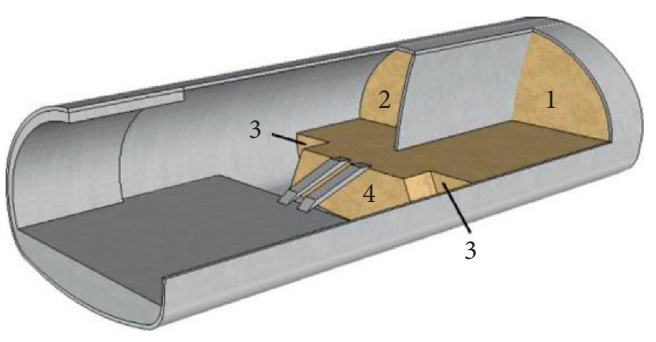

(c)

Figure 1: Construction sequence diagram. (a) CD method. (b) Upper-bench CD method. (c) Three-dimensional hint.

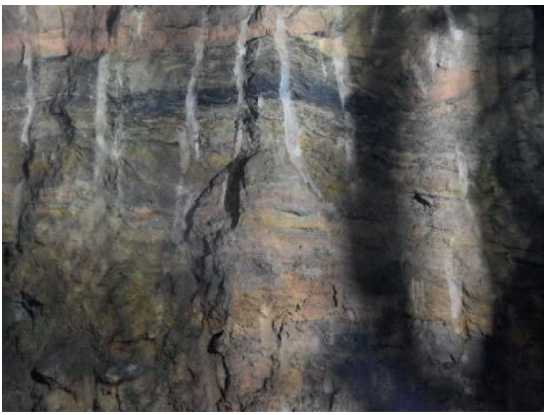

FIGURE 2: Rock mass of palm face.

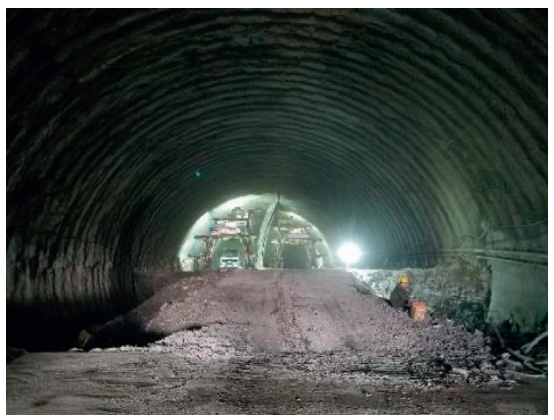

FIgURE 3: Field construction drawing.

3.2.2. Stress Analysis of Steel Frame. The stress time-state curves of the steel frames in Figures 9 and 10 show that the stress of steel frame presents three stages, namely, growth, slow decrease, and stability. Stress growth indicates that the steel frame plays a supporting role in the supporting structure, and the fluctuation is due to the interaction of the various stages of tunnel construction. The first redistribution of the rock mass pressure after initial support construction slowly decreases the stress. After the second lining construction, the second pressure redistribution of the rock mass occurs until the final stability [27] (outside refers to the steel frame flange near the side of the surrounding rock, and inside refers to the steel frame flange away from the side of the rock mass). Steel wire sensor is used to test the stress of steel bar and concrete. A large amount of hydration heat produced by concrete pouring causes temperature drift of the sensor. With the dissipation of hydration heat, the stress tends to be stable.
3.2.3. Stress Analysis of Secondary Lining Reinforcement. The stress of the secondary lining steel bar in Figure 11 indicates that the arch is tensioned, the inverted arch is compressed, and the overall force is small. The maximum compressive stress is $55 \mathrm{MPa}$, and the maximum tensile stress is $27 \mathrm{MPa}$, which are significantly less than the ultimate compressive and tensile strength of the steel bar of $400 \mathrm{MPa}$. This result shows that the stress of the secondary lining steel bar is reasonable and has a certain safety reserve.

3.2.4. Stress Analysis of Secondary Lining Concrete. The stress of the secondary lining concrete in Figure 12 shows that the stress distribution is symmetrical, and the entire concrete is under tension. The maximum tensile stress of the arch is $2.47 \mathrm{MPa}$, which is larger than the tensile strength of $\mathrm{C} 30$ and $2.2 \mathrm{MPa}$. After reaching the maximum tensile stress, each point decreases in varying degrees. Meanwhile, the contact pressure between the initial support and the secondary lining of the arch is small, and no obvious concrete cracking is found in the field. Therefore, the main cause of the tensile stress in the arch is the effect of temperature stress. The second lining is cast in winter, and a large amount of hydration heat causes a temperature difference between the inside and outside of concrete, which results in stress. The reasons for the large overall tension stress of the inverted arch are the large tunnel span, low flat ratio, and small inverted arch thickness and curvature.

\section{Safety Evaluation of Supporting Structures}

4.1. Safety Analysis of Initial Support. To analyze the internal force state and stability of the initial support, we carry out the strength check and safety evaluation of the steel frame under the main load. Given that the steel frame is an eccentric member of the compression-bending combination, the stress distribution of the steel frame in the same section is assumed to be linear, as shown in Figure 13.

According to the stress results of the upper and lower flanges at each measuring point of the steel frame, the axial force and bending moment of the steel frame can be calculated by using the formula of material mechanics. The axial force and bending moment of the steel frames can be calculated as follows: 


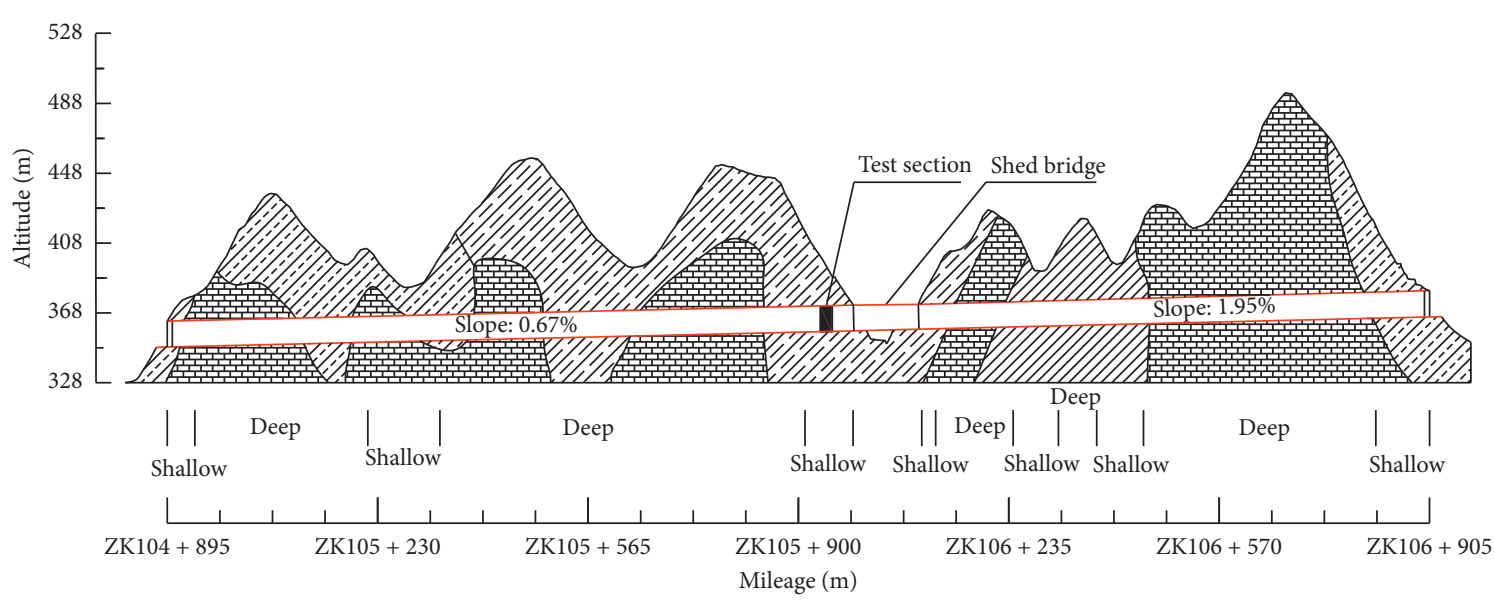

而罣 Moderately weathered limestone and marl BQ = 372 396

Strong and weathered limestone and marl BQ = 194 224

Strong and moderately weathered limestone and marl BQ $=291 \sim 324$

Strong and moderately weathered limestone and marl $\mathrm{BQ}=239 \sim 272$

Figure 4: Longitudinal section of tunnel.

TABLE 1: Field test items.

\begin{tabular}{|c|c|c|c|c|}
\hline Serial number & Test item & Instrument & Specification & Test frequency \\
\hline 1 & Crown settlement & Total station & Accuracy: $1 \mathrm{~mm}$ & $\begin{array}{c}1 \text { day-30 days } 1 \text { time/day } \\
30 \text { days later } \\
2-3 \text { times/week }\end{array}$ \\
\hline 2 & Horizontal convergence & Total station & Accuracy: $1 \mathrm{~mm}$ & $\begin{array}{cc}1 \text { day-30 days } & 1 \text { time/day } \\
30 \text { days later } & 2-3 \text { times/week }\end{array}$ \\
\hline 3 & Shotcrete stress & Concrete strain gauge & $\mathrm{C} 25$ & 1 time/day \\
\hline 4 & Stress of steel frame & Steel string surface strain gauge & $2000 \mu \varepsilon$ & 1 time/day \\
\hline 5 & Secondary lining concrete stress & Concrete strain gauge & $\mathrm{C} 30$ & 1 time/day \\
\hline 6 & Secondary lining reinforcement stress & Steel stress meter & HRB400 & 1 time/day \\
\hline
\end{tabular}

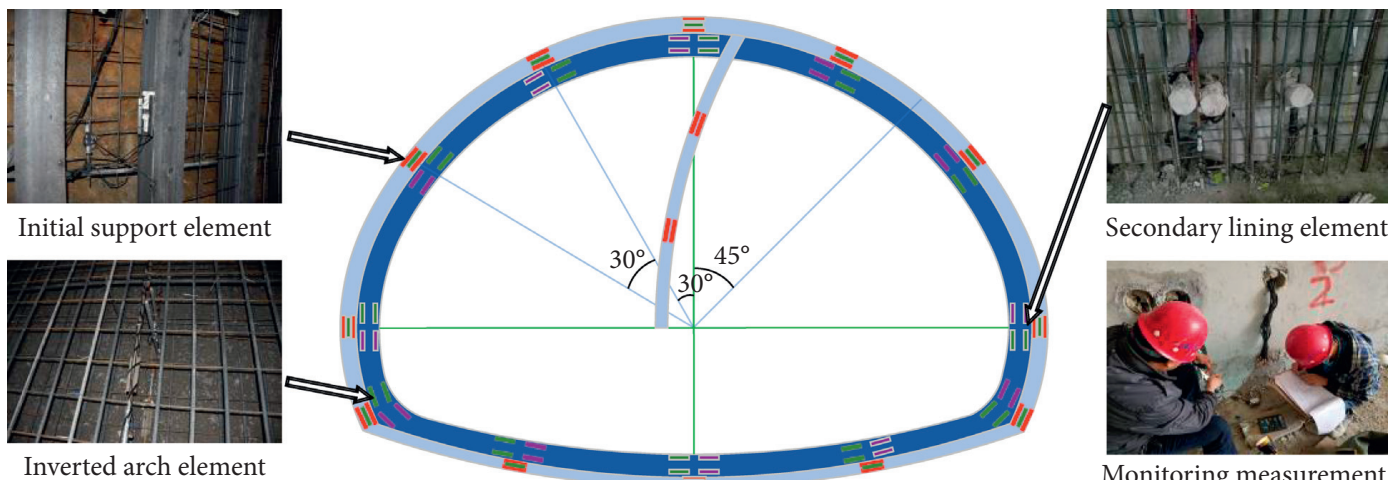

Figure 5: Layout of measuring points.

$$
\begin{aligned}
& \sigma_{1}=\frac{M}{W}+\frac{N}{A}, \\
& \sigma_{2}=-\frac{M}{W}+\frac{N}{A},
\end{aligned}
$$

where $\sigma_{1}$ and $\sigma_{2}$ are the stresses of the upper and lower flanges of the steel frame, respectively; $M$ is the steel frame bending moment; $\mathrm{N}$ is the steel frame axial force; $\mathrm{W}$ is the steel frame section coefficient; and $A$ is the steel frame section area.
The comprehensive safety factor method is used to check the strength and evaluate the safety of the internal force of the steel frame. The steel frame's strength should conform to the stipulations of the following equations:

$$
\begin{aligned}
& K_{g}\left(\frac{N_{g}}{A_{g}}+\frac{M_{g}}{W_{g}}\right) \leq R_{g y}, \\
& K_{g}\left(\frac{N_{g}}{A_{g}}-\frac{M_{g}}{W_{g}}\right) \leq R_{g l},
\end{aligned}
$$




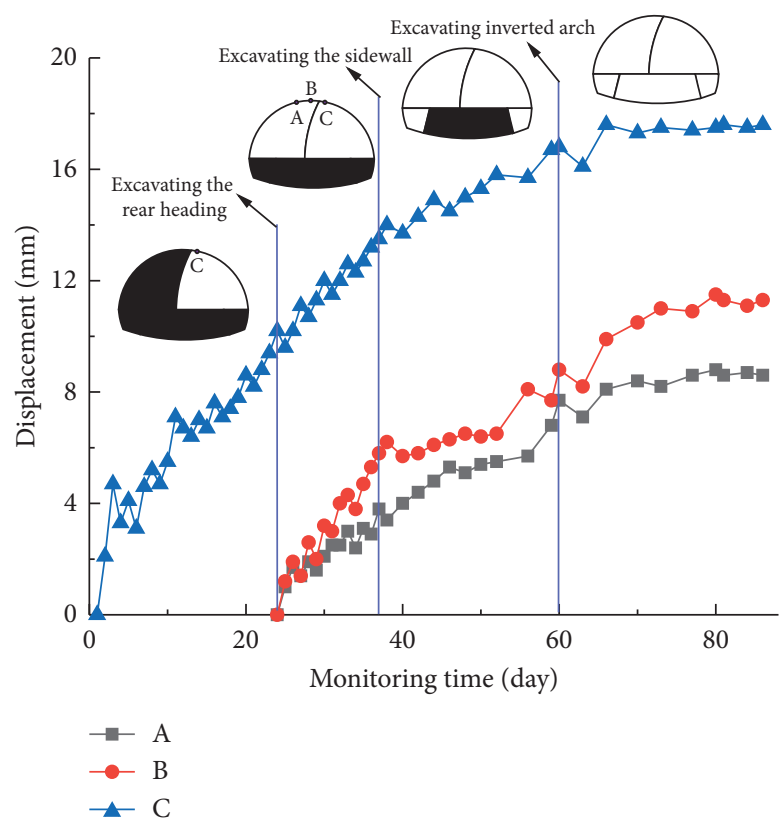

Figure 6: Temporal curve of crown settlement.

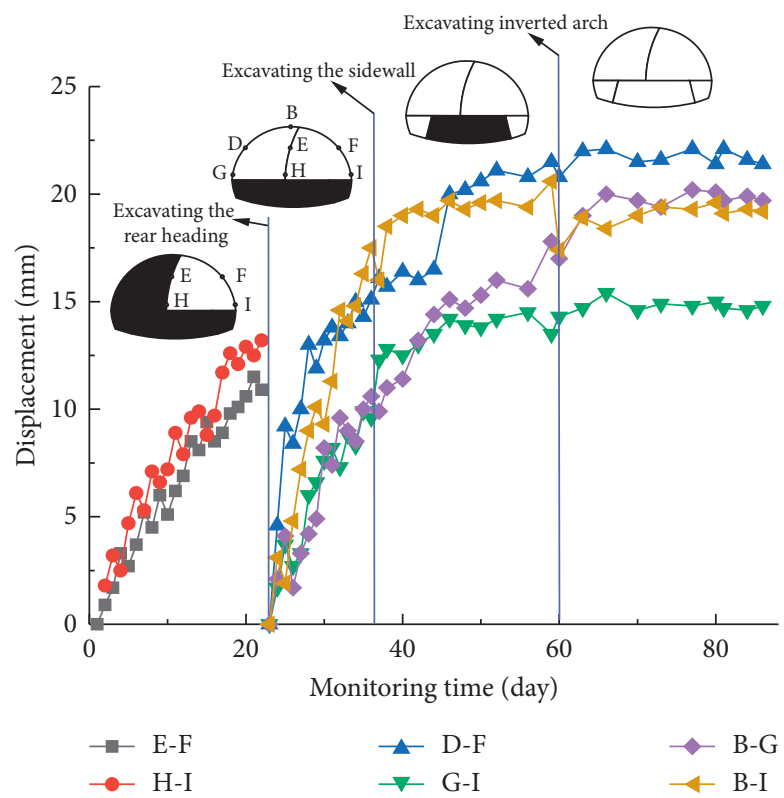

FIgURE 7: Temporal curve of horizontal convergence.

where $R_{g y}$ is the ultimate compressive strength of the steel frame, $R_{g l}$ is the ultimate tensile strength of the steel frame, $K_{g}$ is the comprehensive safety factor of compressive and tensile strength of the steel frame, and $W_{g}$ is the checking calculation of section flexural rigidity of the steel frame.

The safety evaluation of the initial support steel frame is listed in Table 2. The table shows that the maximum axial force and bending moment at each measuring point of the steel frame vary widely, which indicates that the stress of the steel frame is complex and changeable. Considering the large amount of hydration heat produced by the advance of the construction process and the secondary lining, the steel frame fluctuates considerably. Thus, the safety factors of maximum stress and stability stress are calculated. The minimum safety factors of compression and tension are 1.26 at the left arch foot (B7) and 1.36 at the left arch foot, which do not exceed the ultimate bearing capacity of the steel frame. When the supporting ring is closed, and the structure reaches a stable state, the minimum safety factors of compression and tension are 1.69 and 1.78, respectively, which meet the requirements of the tunnel design code for the minimum safety factor of 1.5 . This result shows that the H200 steel frame meets the requirements of the initial support for strength. 

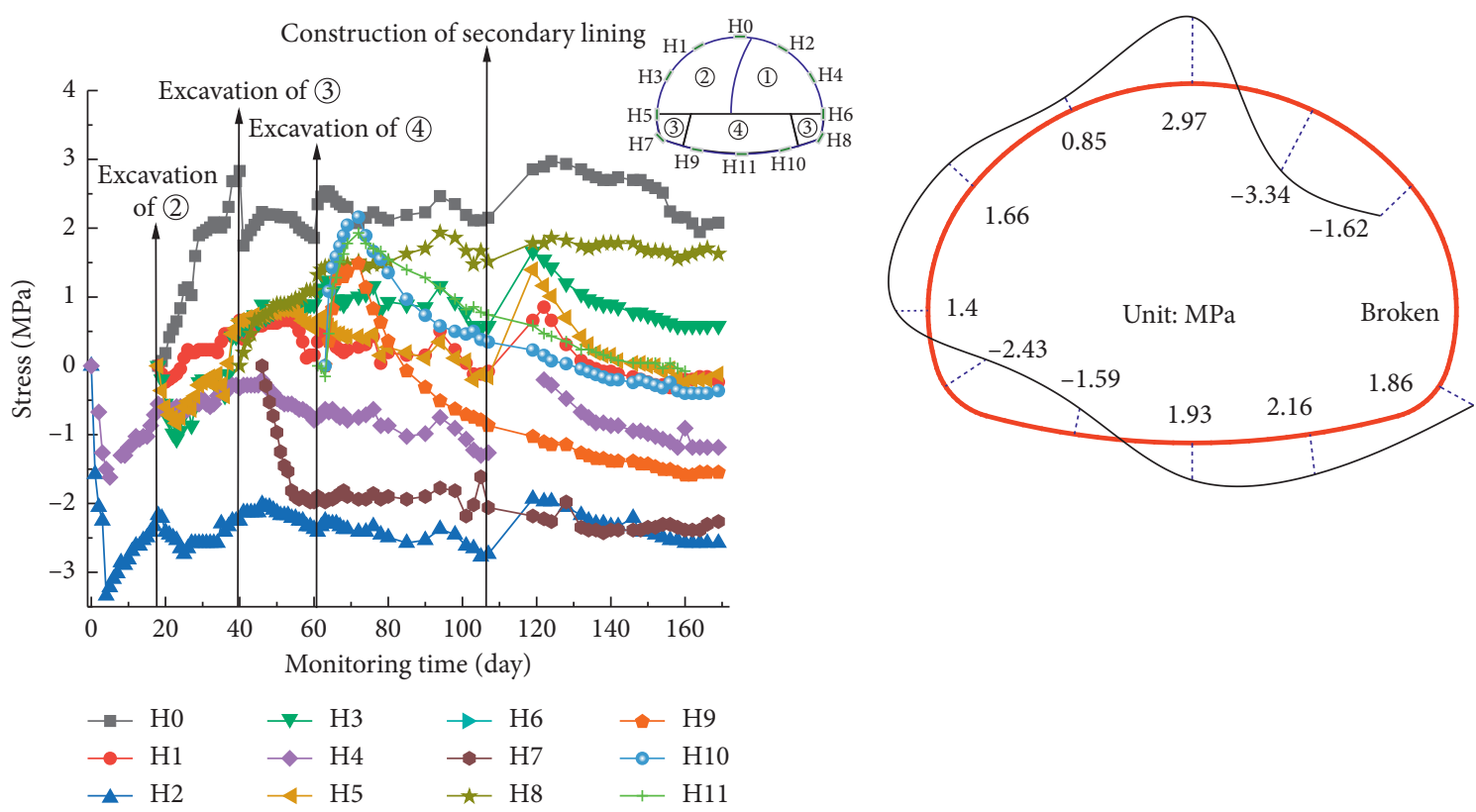

(a)

(b)

Figure 8: Shotcrete stress (“+” for compression, “-” for tension, and unit: MPa). (a) Temporal curve. (b) Contact pressure distribution.

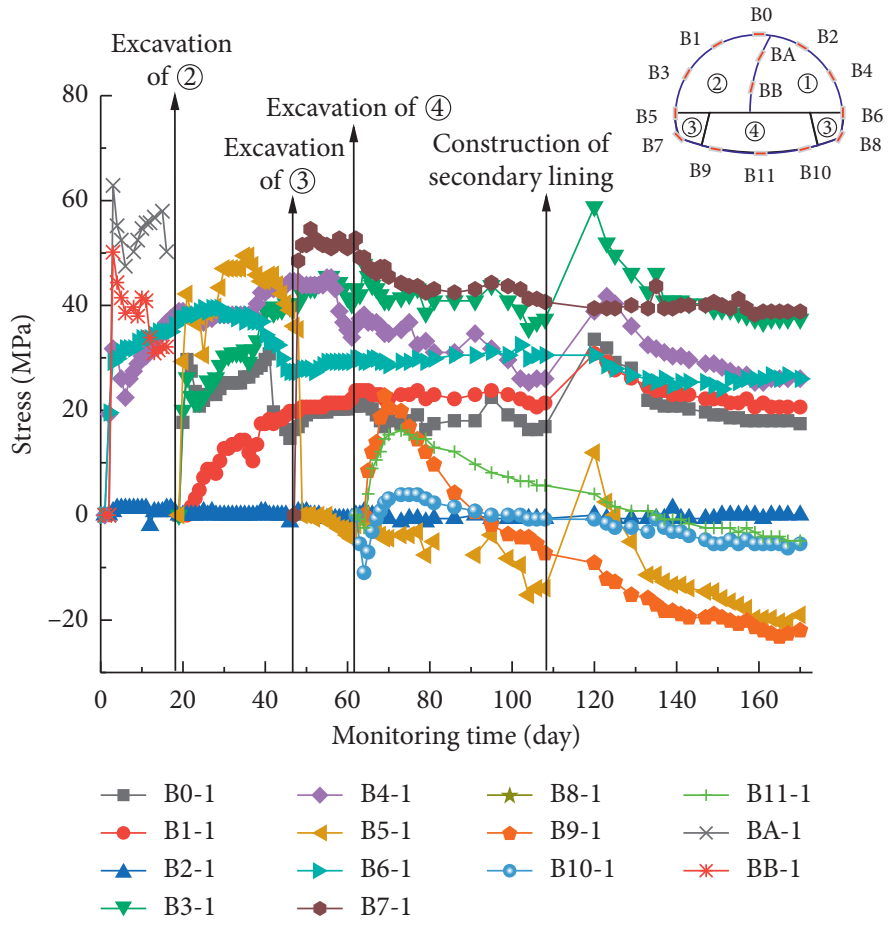

(a)

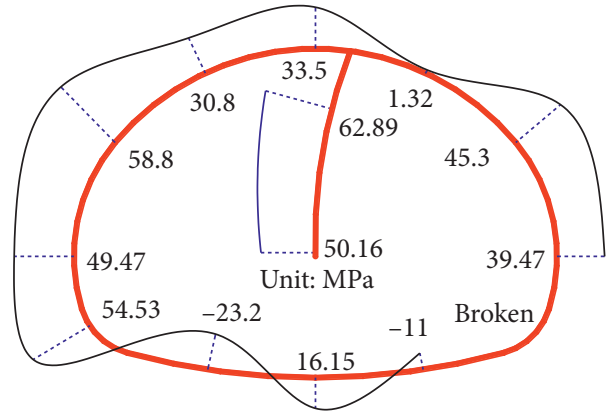

(b)

Figure 9: Outside stress of steel frame (“+” for compression, “-” for tension, and unit: MPa). (a) Temporal curve. (b) Contact pressure distribution.

4.2. Safety Analysis of Secondary Lining. The secondary lining is a large-volume-reinforced concrete structure whose actual force is extremely complex. To calculate the force of the secondary lining analytically, we carry out a simplified analysis [28]. The mechanical model of the rectangular element is established by taking a calculating unit of the lining structure and simplifying the curved beam element to a rectangular element. The force of the structure can be simplified to the calculation of eccentric compressive members in which concrete and longitudinal steel bars bear 


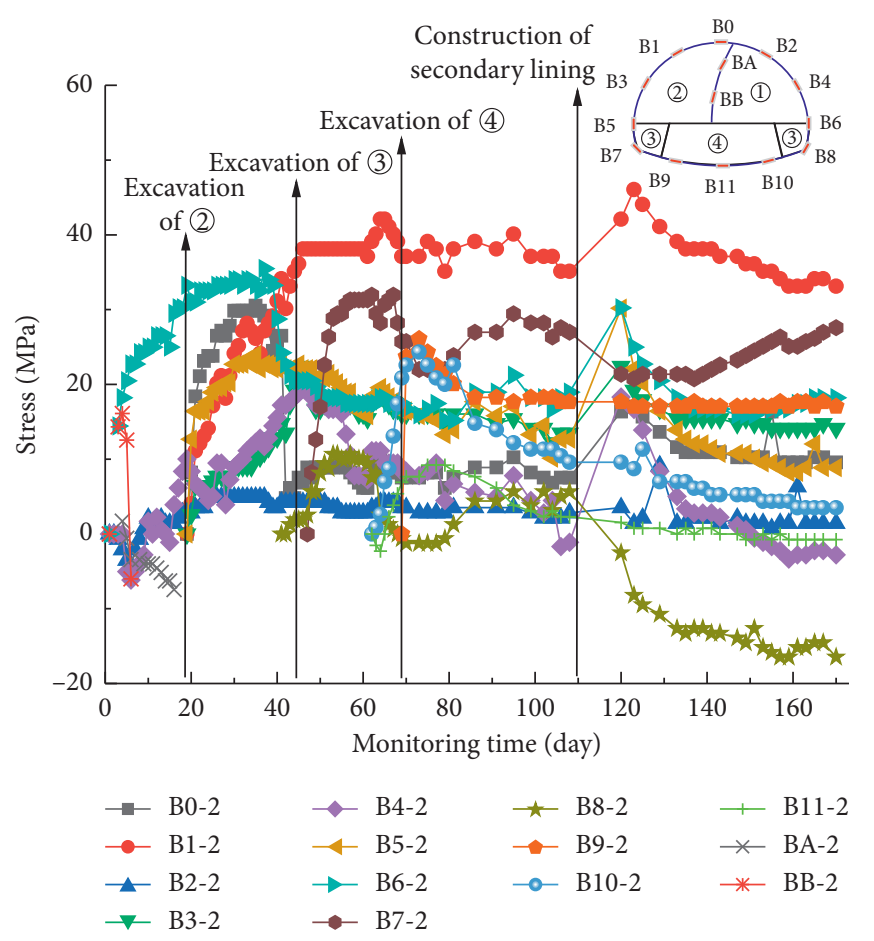

(a)

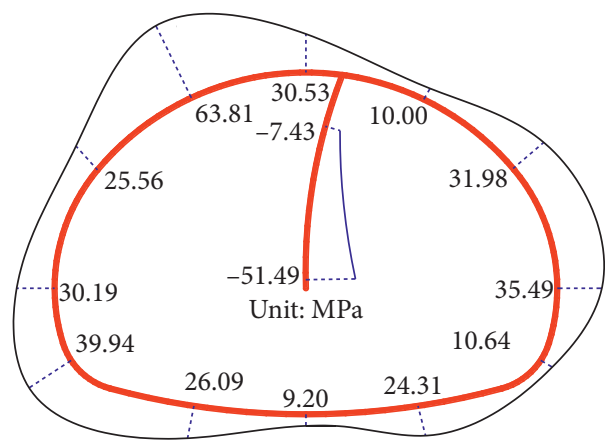

(b)

Figure 10: Inside stress of steel frame (“+” for compression, “-” for tension, and unit: MPa). (a) Temporal curve. (b) Contact pressure distribution.

the pressure, and the calculation sketch of the lining internal force is shown in Figure 14. The figure shows that $P_{1}$ and $P_{2}$ represent the concentrating force of the steel bars on the outside and inside, respectively; $P_{C}$ is the average concentrating force of concrete; $M$ and $N$ are the bending moment and axial force of the section, respectively; $a$ is the thickness of protective layer of the steel bars; $b$ is the thickness of the lining; and $c$ is the spacing of the longitudinal steel bars.

(1) Static equilibrium conditions: under eccentric pressure, $\sigma_{s 1}$ is the stress of the outer reinforcement of the lining; $\sigma_{s 2}$ is the stress of the inner reinforcement; $\varepsilon_{1}$ and $\varepsilon_{2}$ are the corresponding strains of the steel bar; $A$ is the area of the longitudinal section of the lining; $A_{s}$ is the area of the longitudinal section of the reinforcement; and $\sigma_{c 1}$ and $\sigma_{c 2}$ are the stresses of the outer and inner concretes of the corresponding position, respectively:

$$
\begin{aligned}
& N=\frac{1}{2}\left(\sigma_{c 1}+\sigma_{c 2}\right) A+\left(\sigma_{s 1}+\sigma_{s 2}\right) A_{s}, \\
& M=\left(P_{1}-P_{2}\right)\left(\frac{b}{2}-a\right)+\frac{1}{2} b\left(\sigma_{c 1}-\sigma_{c 2}\right) A .
\end{aligned}
$$

(2) Plane deformation conditions: in the equation above, $\varepsilon_{s}$ is the steel bar strain, $\varepsilon_{c}$ is concrete strain, and $\varepsilon$ is the cross section strain:

$$
\varepsilon_{s}=\varepsilon_{c}=\varepsilon
$$

(3) Physical conditions: according to the constitutive relation of the stress and strain of the steel bar and concrete under compression, the structural stress can be divided into three stages: the elastic-plastic, yield, and failure stages. The formulas are as follows:

$$
\begin{aligned}
\text { steel bar: } \sigma_{s} & =E_{s} \cdot \varepsilon_{s} \cdots\left(0 \leq \varepsilon_{s} \leq \varepsilon_{y}\right), \\
\sigma_{s} & =\sigma_{y} \cdots\left(\varepsilon_{y} \leq \varepsilon_{s}\right), \\
\text { concrete: } \sigma_{c} & =\sigma_{0}\left[2 \cdot \frac{\varepsilon}{\varepsilon_{0}}-\left(\frac{\varepsilon}{\varepsilon_{0}}\right)^{2}\right] \cdots\left(\varepsilon \leq \varepsilon_{0}\right), \\
\sigma_{c} & =\sigma_{0} \cdots\left(\varepsilon_{0}<\varepsilon<\varepsilon_{\mathrm{cu}}\right),
\end{aligned}
$$

where $\varepsilon_{y}$ is the yield strain of the steel bar (that of the HRB400 steel bar is 0.0019), $\sigma_{y}$ is the yield stress of the steel bar, $\sigma_{0}$ is the peak stress $\left(0.85 f_{\mathrm{cu}}\right), f_{\mathrm{cu}}$ is the standard compressive strength of concrete, $\varepsilon_{0}$ is the peak strain $(0.002)$, and $\sigma_{\mathrm{cu}}$ is the limit strain (0.0035).

Elastic-plastic stage: steel bar is regarded as an ideal homogeneous elastic body. Considering the inelastic properties of concrete materials, the axial force formulas 

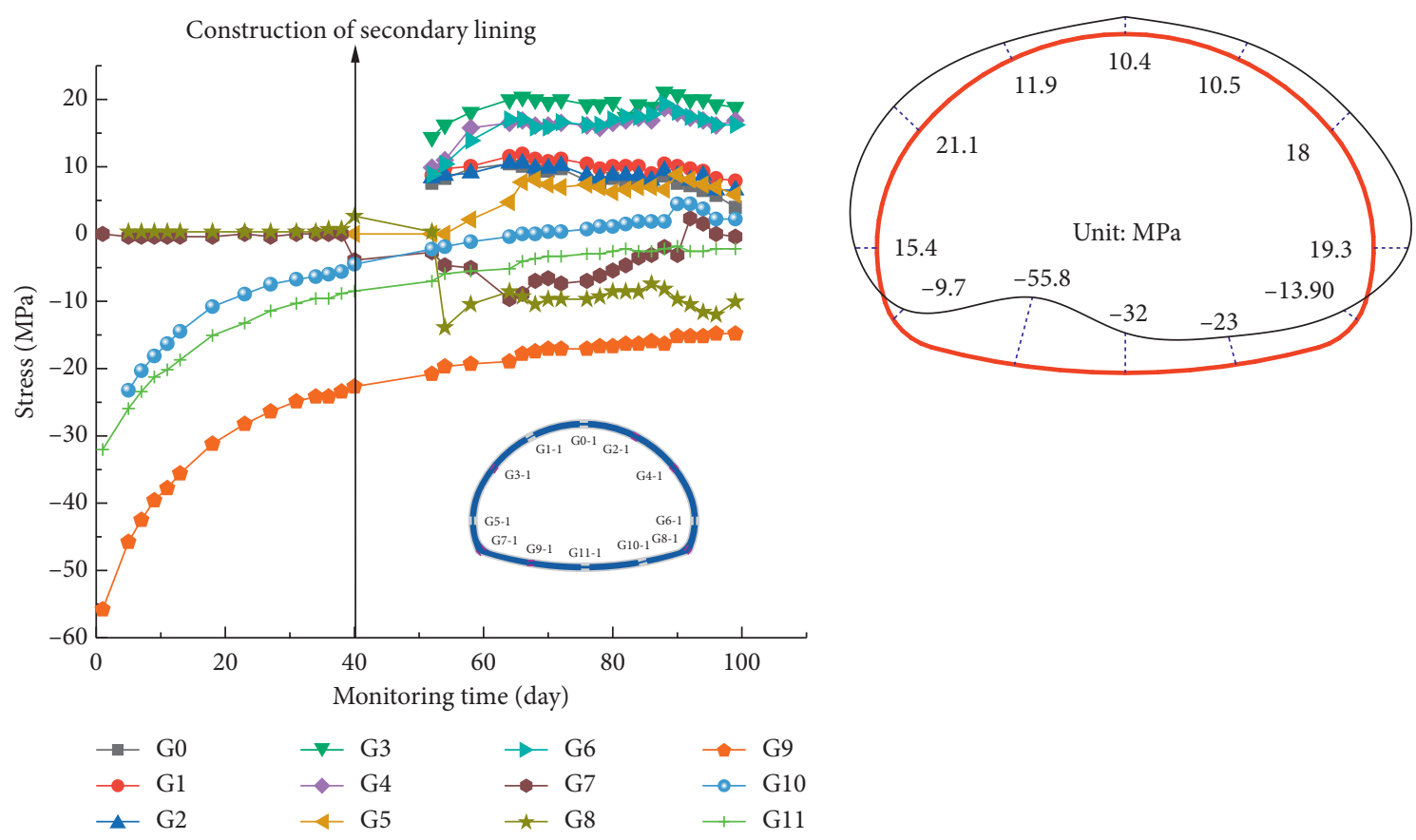

(a)

(b)
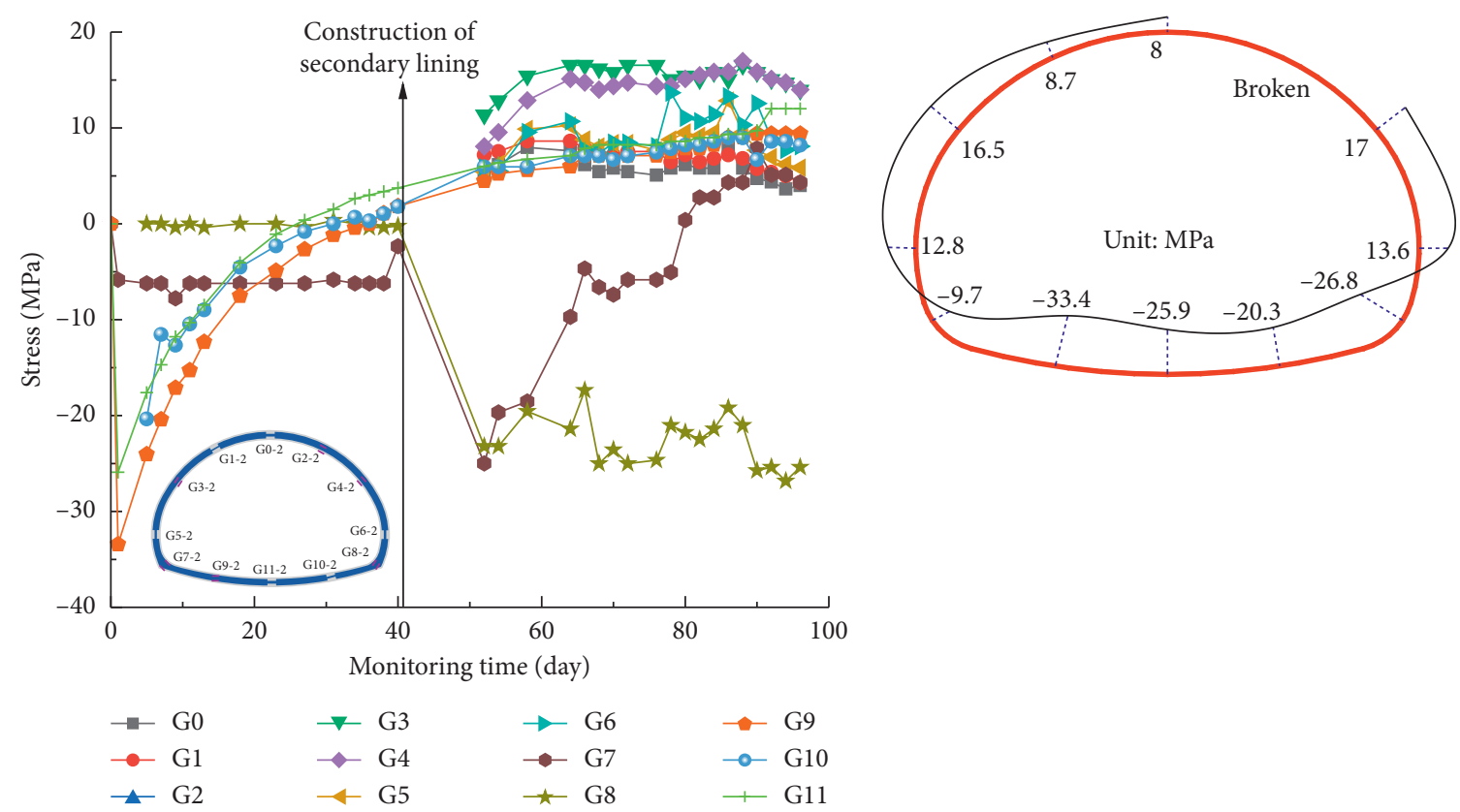

(c)

(d)

Figure 11: Stress of secondary lining steel bar (“+” for tension, “-” for compression, and unit: MPa). (a) Lateral temporal curve. (b) Maximum lateral stress distribution. (c) Medial temporal curve. (d) Maximum stress distribution inside.

are derived by substituting (6) and (8) into (4). The calculation method of bending moment is similar to that of other methods, as follows:

$$
N=\frac{1}{2}\left(\sigma_{0}\left[2 \cdot \frac{\varepsilon_{c 1}}{\varepsilon_{0}}-\left(\frac{\varepsilon_{c 1}}{\varepsilon_{0}}\right)^{2}\right]+\sigma_{0}\left[2 \cdot \frac{\varepsilon_{c_{c 2}}}{\varepsilon_{0}}-\left(\frac{\varepsilon_{c_{2}}}{\varepsilon_{0}}\right)^{2}\right]\right) A+\left(E_{s} \varepsilon_{s 1}+E_{s} \varepsilon_{s 2}\right) A_{s} .
$$

Yield stage: when the steel bar reaches the yield strain and the corresponding concrete strain is less than the peak strain $(0.19<\varepsilon<0.20)$, (7) and (9) are substituted into (4) to obtain the formula of axial force, as follows:

$$
N=\frac{1}{2}\left(\sigma_{0}\left[2 \cdot \frac{\varepsilon_{c 1}}{\varepsilon_{0}}-\left(\frac{\varepsilon_{c 1}}{\varepsilon_{0}}\right)^{2}\right]+\sigma_{0}\left[2 \cdot \frac{\varepsilon_{c 2}}{\varepsilon_{0}}-\left(\frac{\varepsilon_{c 2}}{\varepsilon_{0}}\right)^{2}\right]\right) A+2 \sigma_{y} \cdot A_{s} .
$$

Failure stage: when the structural strain exceeds the peak strain of concrete $(\varepsilon>0.20)$, the structural pressure 

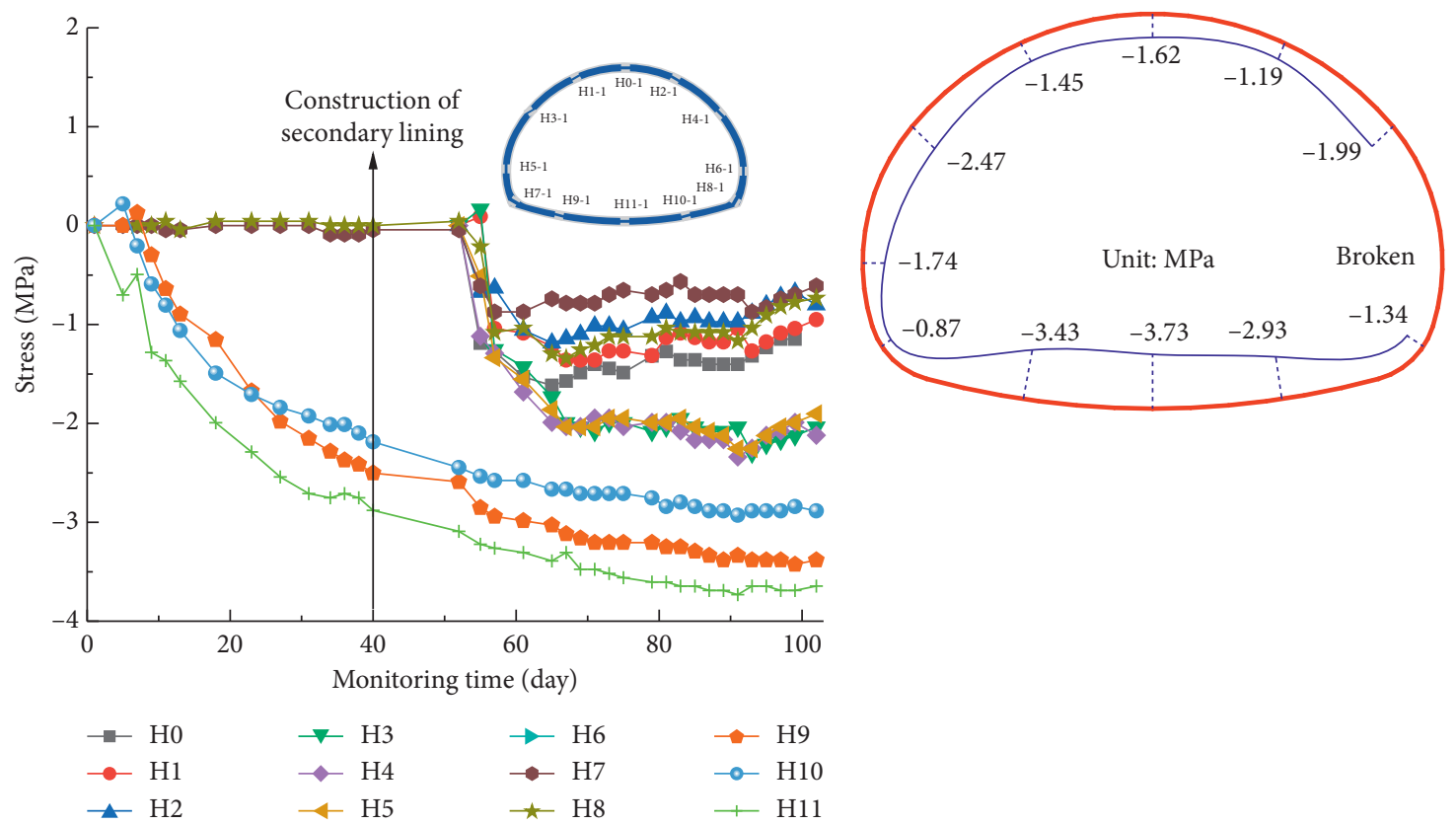

(a)

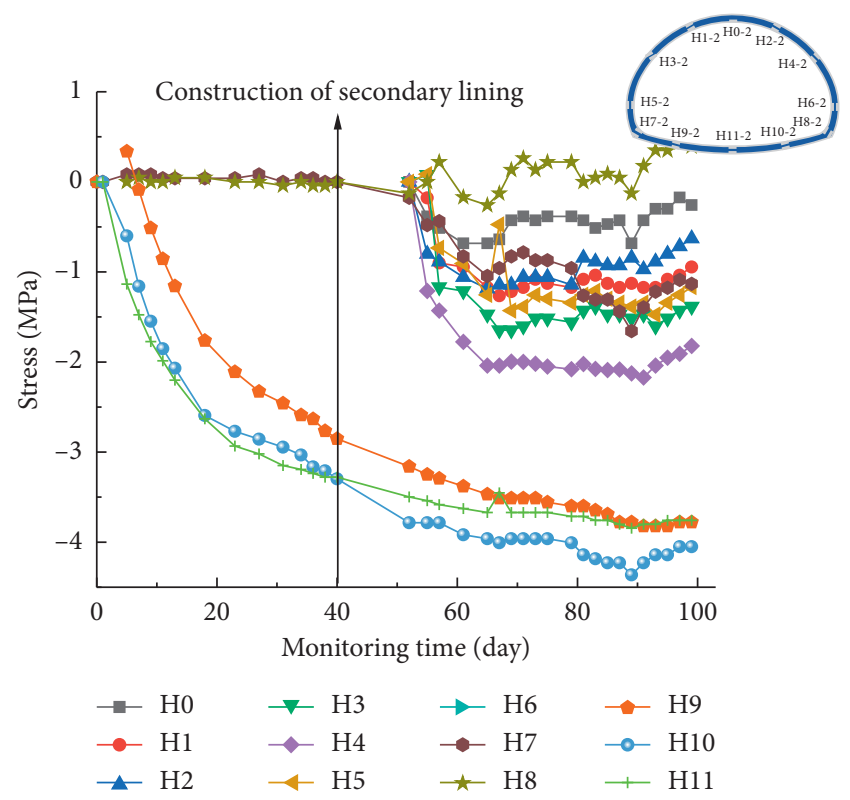

(b)

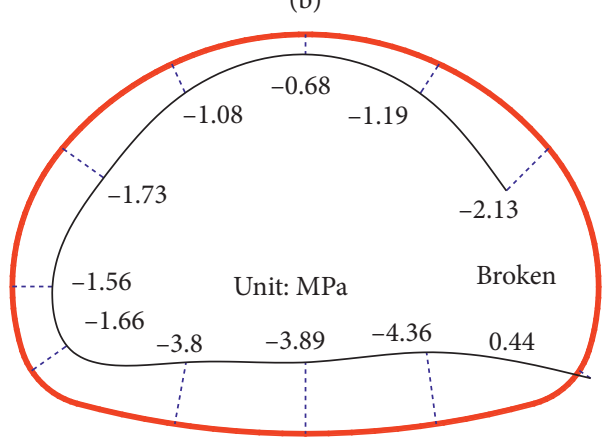

(c)

(d)

FIGURE 12: Stress distribution of secondary lining concrete (“+” for compression, “-” for tension, and unit: MPa). (a) Lateral temporal curve. (b) Maximum lateral stress distribution. (c) Medial temporal curve. (d) Maximum stress distribution inside.

remains unchanged, thereby resulting in irreversible continuous deformation until failure.

The yield stress of the steel bar is $400 \mathrm{MPa}$, the modulus of elasticity is $210 \mathrm{GPa}$, and the maximum compressive stress is $55.8 \mathrm{MPa}$. The strain of the steel bar is 0.00026 , which is much less than the yield strain of the steel bar of 0.0019 . The maximum strain of concrete is 0.00014 , which is also less than the peak strain of 0.002 . Therefore, the stress of the lining is in the elastic-plastic stage:

$$
\begin{aligned}
N= & \frac{1}{2}\left(17.1\left[2 \cdot \frac{\varepsilon_{c 1}}{0.002}-\left(\frac{\varepsilon_{c 1}}{0.002}\right)^{2}\right]+17.1\left[2 \cdot \frac{\varepsilon_{c 2}}{0.002}-\left(\frac{\varepsilon_{c 2}}{0.002}\right)^{2}\right]\right) 10^{6} A \\
& +2.1\left(\varepsilon_{s 1}+\varepsilon_{s 2}\right) A_{s} 10^{11} \\
M= & 2.1\left(\varepsilon_{s 1}-\varepsilon_{s 2}\right)\left(\frac{b}{2}-a\right) A_{s} 10^{11}+1.55 b\left(\varepsilon_{c 1}-\varepsilon_{c 2}\right) A 10^{10} .
\end{aligned}
$$

Substituting the calculated axial force and the bending moment into the formula of comprehensive safety factor can obtain the safety factor of the secondary lining, as follows: 


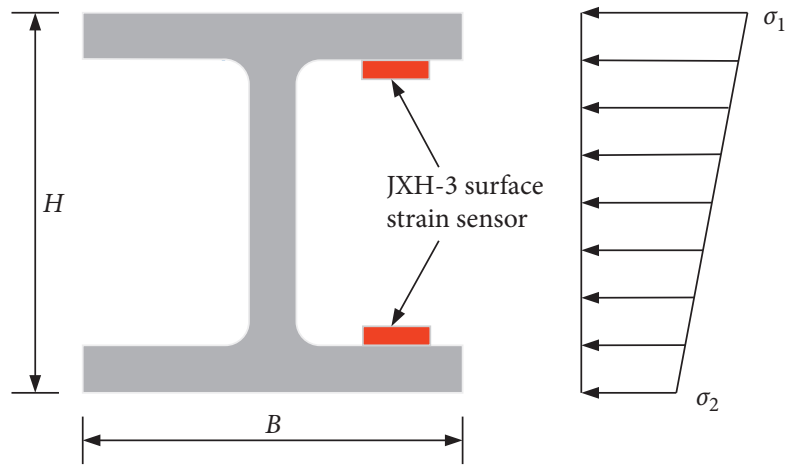

FIGURE 13: Force diagram of steel frame.

TABLE 2: Safety evaluation of initial support.

\begin{tabular}{|c|c|c|c|c|c|c|}
\hline \multirow[b]{2}{*}{ Position } & \multirow{2}{*}{$\begin{array}{l}\text { Maximum axis force } \\
(\mathrm{kN})\end{array}$} & \multirow{2}{*}{$\begin{array}{l}\text { Maximum bending moment } \\
\qquad(\mathrm{kN} \cdot \mathrm{m})\end{array}$} & \multicolumn{2}{|c|}{ Compressive safety factor } & \multicolumn{2}{|c|}{ Tensile safety factor } \\
\hline & & & $\begin{array}{l}\text { Minimum } \\
\text { value }\end{array}$ & $\begin{array}{c}\text { Stability } \\
\text { value }\end{array}$ & $\begin{array}{l}\text { Minimum } \\
\text { value }\end{array}$ & $\begin{array}{c}\text { Stability } \\
\text { value }\end{array}$ \\
\hline B0 & 1935 & 3.3 & 1.3 & 3.9 & 1.36 & 4.27 \\
\hline B1 & 1751 & -3.6 & 1.51 & 2.18 & 1.43 & 2.04 \\
\hline B2 & 141 & 0.9 & 19.8 & 93.9 & 16.8 & 70.7 \\
\hline B3 & 1849 & 8.7 & 1.31 & 2.07 & 1.48 & 2.35 \\
\hline B4 & 1473 & 6.1 & 1.65 & 4.14 & 1.85 & 5.9 \\
\hline B5 & 1812 & 4.6 & 1.37 & 7.28 & 1.47 & 15.5 \\
\hline B6 & 1708 & 1 & 1.48 & 2.49 & 1.51 & 2.62 \\
\hline B7 & 1967.3 & 5.4 & 1.26 & 1.69 & 1.36 & 1.78 \\
\hline B9 & 63.7 & -11.7 & 27.2 & 9.27 & 11.6 & 6.4 \\
\hline B10 & 303 & -8.4 & 13.6 & 34.5 & 6.2 & 154.8 \\
\hline B11 & 576 & 1.6 & 4.3 & 25 & 4.64 & 16.4 \\
\hline
\end{tabular}

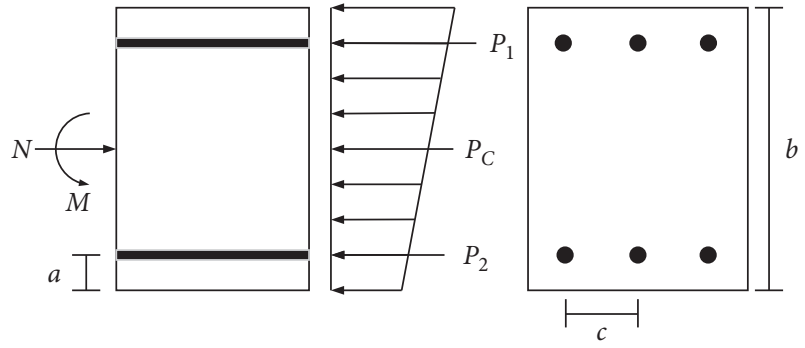

FIgURE 14: Brief drawing of lining internal force calculation.

$$
\begin{aligned}
& \mathrm{KM} \leq f_{c k} b x\left(h_{0}-\frac{x}{2}\right)+R_{g}^{\prime} A_{g}^{\prime}\left(h_{0}-a_{g}^{\prime}\right), \\
& \mathrm{KN} \leq R_{a} b x+R_{g}^{\prime} A_{g}^{\prime}\left(h_{0}-a_{g}^{\prime}\right),
\end{aligned}
$$

where $x$ is the height of the concrete compression zone, $R_{g}^{\prime}$ is the standard compressive strength of the longitudinal steel bar, $A_{g}^{\prime}$ is the area of the longitudinal compression steel bar, $h_{0}$ is the effective height of the section, and $a_{g}^{\prime}$ is the distance from the resultant point of the longitudinal compression steel bar to the compression edge.

The maximum reinforcement and concrete stress data of the secondary lining are substituted, and the axial force and bending moment of the secondary lining are calculated, and a small value is taken as the structural safety factor according to (14) and (15).

The safety evaluation of the secondary lining is performed as listed in Table 3. The table indicates that the secondary lining structure has complex stress, especially the bending moment has a wide range of variation. The calculated safety factor is $>2$, and the minimum safety factor is 3.8, thereby fully satisfying the stress requirements of the secondary lining structure in tunnel design and providing sufficient safety reserves.

\section{Numerical Simulation Analysis}

The excavation and support of underground caverns is a multistep process. Every excavation and support will have an impact on the support structure. Therefore, the underground engineering structure system is always in the complicated process of loading and unloading during the construction process [29]. In view of the complex and changeable mechanical characteristics of super largespan highway tunnel construction, the tunnel excavation and support process is simulated by the finite difference software FLAC3D, and the displacement of the rock mass 
TABLE 3: Safety evaluation of secondary lining.

\begin{tabular}{lccc}
\hline Position & $\begin{array}{c}\text { Maximum axis } \\
\text { force }(\mathrm{kN})\end{array}$ & $\begin{array}{c}\text { Maximum bending } \\
\text { moment }(\mathrm{kN} \cdot \mathrm{m})\end{array}$ & $\begin{array}{c}\text { Safety } \\
\text { factor }\end{array}$ \\
\hline B0 & 96.7 & 46.2 & 11.6 \\
B1 & 106.6 & 18.5 & 7.2 \\
B3 & 177.6 & 36.8 & 3.8 \\
B4 & 173.4 & -6.7 & 14.8 \\
B5 & 139.4 & 9.1 & 12.7 \\
B7 & 90.4 & -37.4 & 10.4 \\
B8 & 13.6 & 88.8 & 23.8 \\
B9 & 225.4 & -21.4 & 13.3 \\
B10 & 250.2 & -70.2 & 10.5 \\
B11 & 255.2 & -8.7 & 10 \\
\hline
\end{tabular}

and the stress of the support structure under different construction methods are compared and analyzed.

5.1. Computational Model and Parameters. According to the geological conditions of the tunnel and Saint-Venant's principle, the size of the calculation model is larger than three times the maximum excavation span, the depth of the tunnel is $20 \mathrm{~m}$, and the length of the tunnel is $60 \mathrm{~m}$. In summary, the numerical model dimension is $148.5 \mathrm{~m} \times 97.5 \mathrm{~m} \times 60 \mathrm{~m}$, and the comparative analyses of four construction methods (the both-side drift, CRD, CD, and upper-bench CD methods) are simulated. The calculation model and the construction process are shown in Figure 15. When different construction methods are used for tunnel construction simulation, the first is advance support, the second is partial excavation, the third is initial support and anchor bolt, and the last is secondary lining. Refer to Figure 1 for specific excavation sequence.

The model simplifies the engineering practice. The rock mass is regarded as a continuous, homogeneous, and isotropic medium, and the Mohr-Coulomb criterion is adopted for yield. Only the gravity of limestone and marl is considered, and tectonic stress is disregarded. The grouting reinforcement of small pipes ahead of the arch and bolt system are simulated by increasing the cohesion and the internal friction to form the rock mass reinforcement zone [30]. The shell and solid elements are used to simulate the initial support and secondary lining of the composite lining, and the initial support steel frame and the shotcrete are equivalently reduced. The mechanical parameters of the rock mass are based on the survey and design data combined with the current tunnel specifications. The mechanical parameters of the surrounding rock and the supporting structure are shown in Table 4.

5.2. Calculation and Analysis. In eliminating the influence of boundary effect on model calculation, the target surface of the numerical simulation analysis is located $30 \mathrm{~m}$ in the middle of the model.

5.2.1. Contrastive Analysis of Rock Mass Deformation. The analysis of crown settlement in Figure 16 indicates that the pilot tunnel is larger than that at the rear side when the upper-bench CD method is used for excavation, which is consistent with the measured results. The maximum settlement of crown displacement by the upper-bench CD method is $37.8 \mathrm{~mm}$, which satisfies the requirements of displacement control $(120 \mathrm{~mm})$.

The crown settlement curve in Figure 17 shows that the deformation rate increases with the advancement of the palm surface. When the excavation surface reaches the monitoring section, the settlement rate decreases, which indicates that the support structure can effectively control the deformation of the rock mass. When the tunnel is excavated to the front of the section, the surrounding rock has been deformed greatly, each method has a proportion of total settlement in the range of $50 \%-60 \%$, thereby requiring advanced support measures.

Figures 18 and 19 indicate that the maximum horizontal displacement is located at the arch line, and the maximum convergent displacement is $31.3 \mathrm{~mm}$ during the construction of the upper-bench $\mathrm{CD}$ method, which shows that the upper-bench $\mathrm{CD}$ method is weaker than other construction methods in controlling horizontal convergence. When the face of the palm is continuously excavated for approximately $25 \mathrm{~m}$, the deformation tends to stabilize and can be used as the secondary lining.

5.2.2. Contrast of Plastic Zone of Tunnel. Figure 20 indicates that the shape of the plastic zone is approximately symmetrical, and the main plastic zone is in the orthogonal direction of the large principal stress. The plastic zone of the upper-bench CD method is the largest among all methods, and the plastic zone of the CD, CRD, and both-side drift methods decreases in turn. From the failure mode, the tunnel arch waist and inverted arch bottom mainly exhibit shear failure, while tension failure occurs on the surface at approximately $45^{\circ}$ above the tunnel.

5.2.3. Internal Force Analysis of Initial Support. The maximum values of axial force and bending moment of the tunnel's initial support under various construction methods are listed in Table 5.

Table 5 shows that the arch and the side wall are the most vulnerable points of internal force in the construction of super large-span highway tunnels. The axial force and bending moment of the initial support with $\mathrm{CD}$ method are the largest. Compared with the CD method, the axial force and bending moment produced by the upper-bench $\mathrm{CD}$ method are reduced by $8.4 \%$ and $35.2 \%$, respectively. Although the deformation of the surrounding rock is increased, the stress of the rock mass is effectively released by the deformation, which is safe for the supporting structure to bear force. Compared with the field test, the axial force of the initial support is close and the moment difference is large. This is because the established mechanical model only assumes that the steel frame bears the bending moment when the structural stress is transformed into the bending moment, and the shell with the initial support set as no solid element in the numerical simulation has a great influence on 


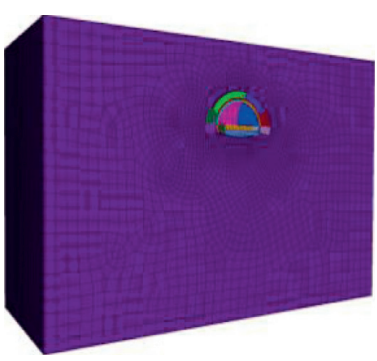

(a)

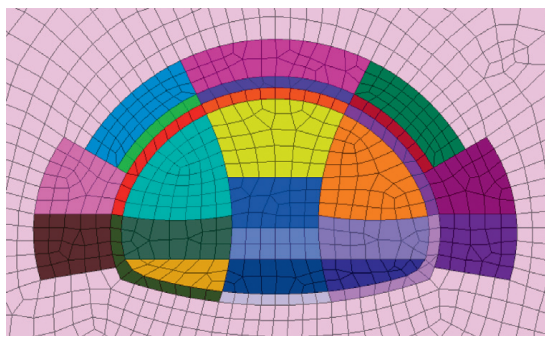

(d)

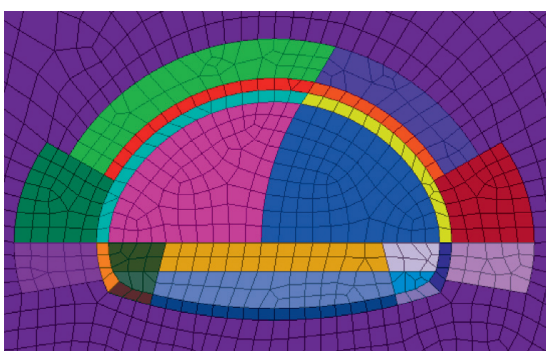

(b)

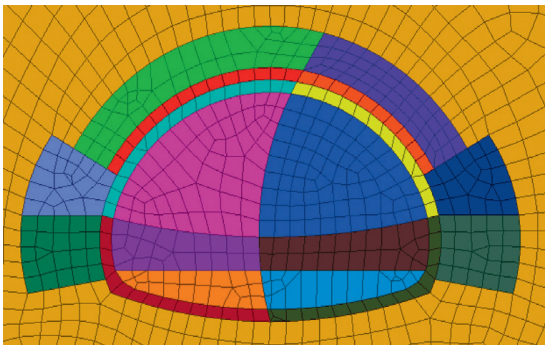

(c)

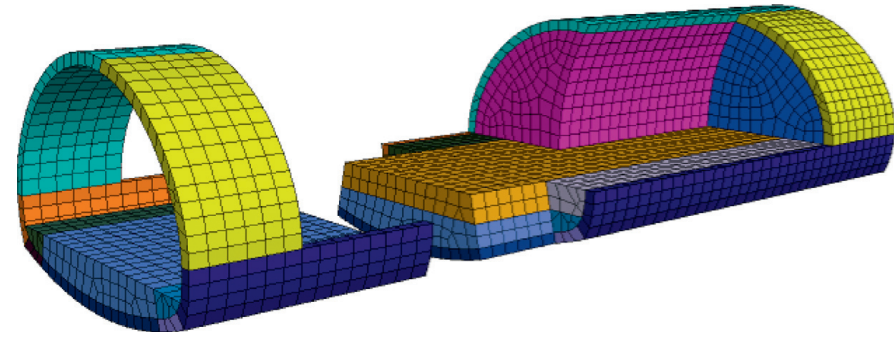

(e)

FIgure 15: Tunnel model. (a) Overall model. (b) Half-part CD model. (c) CD method model. (d) Both-side drift method model. (e) Construction excavation indication.

TABLE 4: The mechanical parameters of rock mass and supporting structure.

\begin{tabular}{lccccc}
\hline Category of materials & $\begin{array}{c}\text { Volumetric weight } \\
\left(\mathrm{kN} \cdot \mathrm{m}^{-3}\right)\end{array}$ & $\begin{array}{c}\text { Modulus of elasticity } \\
(\mathrm{GPa})\end{array}$ & $\begin{array}{c}\text { Poisson's } \\
\text { ratio }\end{array}$ & $\begin{array}{c}\text { Cohesion } \\
(\mathrm{kPa})\end{array}$ & $\begin{array}{c}\text { Internal friction angle } \\
\left({ }^{\circ}\right)\end{array}$ \\
\hline $\begin{array}{l}\text { Rock mass } \\
\text { Grouting reinforcement }\end{array}$ & 2 & 1 & 0.35 & 500 & 21 \\
zone & 2 & 1.05 & 0.35 & 550 & 22 \\
Initial support & & 30.5 & 0.2 & & \\
Temporary support & 7.8 & 29.5 & 0.2 & \\
Feet-lock bolt & 2.5 & 210 & 0.3 & \\
Secondary lining & 2.3 & 31 & 0.2 & \\
Backfilling of inverted arch & & & 0.2 & \\
\hline
\end{tabular}

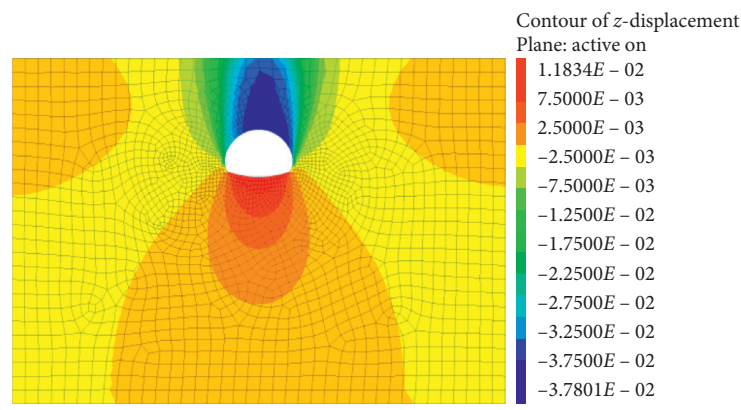

FiguRE 16: Crown settlement diagram of the upper-bench CD method.

the bending moment. However, the overall small bending moment has little effect on the stability of the structure.

5.2.4. Stress Analysis of Secondary Lining. As shown in Figure 21 and Table 6, when the upper-bench CD method is used for construction, maximum tension stress occurs at the inside of the arch waist and the foot of the wall, and maximum compression stress occurs at the outside of the foot of the wall. The comparison of the four construction methods shows that the stress of the entire structure is within the allowable stress range of concrete, and the tension and compression stress of the secondary lining are the smallest when the upper-bench CD method is used for construction. This result shows that the upperbench $\mathrm{CD}$ method is beneficial to the self-supporting 


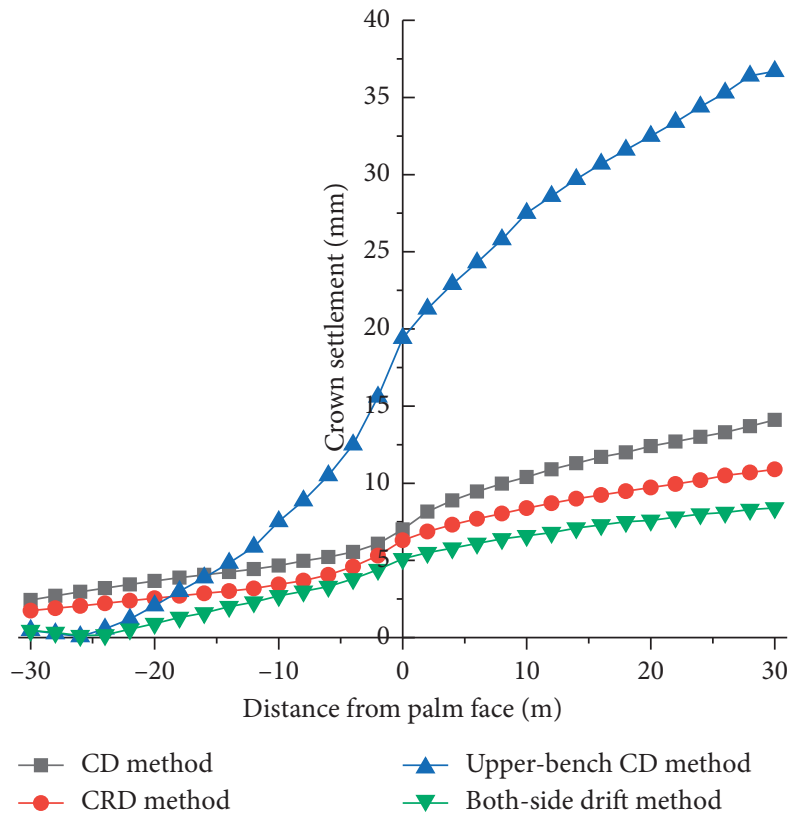

FIgURE 17: Crown settlement curves of different construction methods.

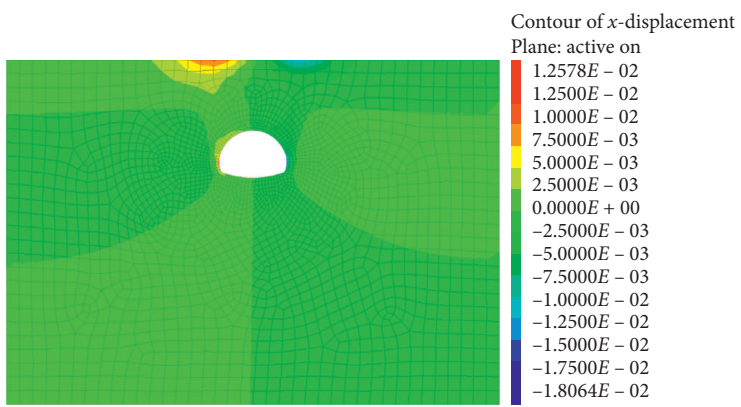

FIGURE 18: Horizontal convergence of the upper-bench CD method.

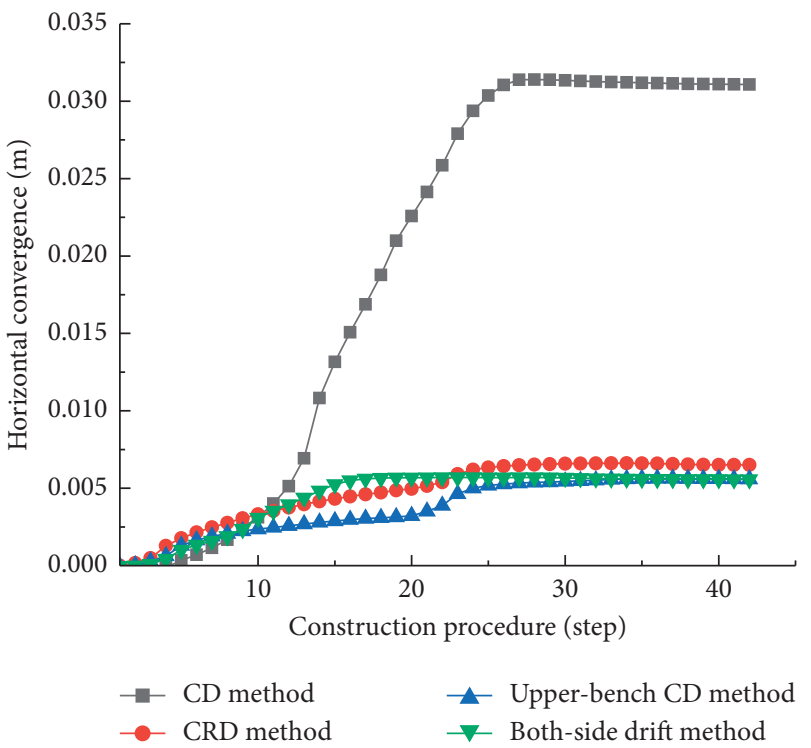

FIGURE 19: Horizontal convergence curves of different construction methods. 


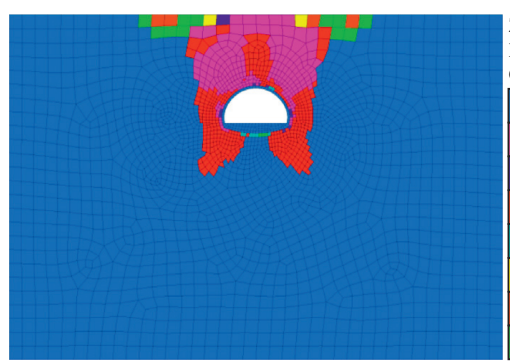

(a)

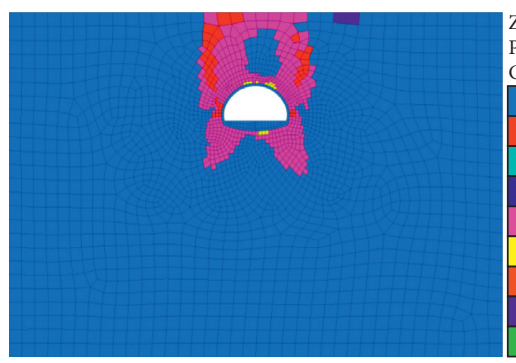

(c)

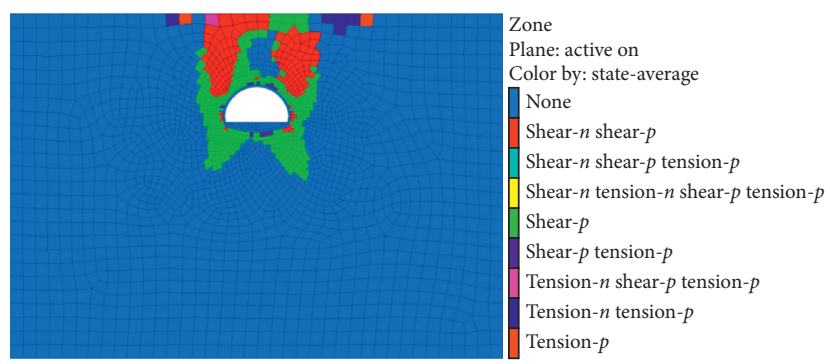

(b)

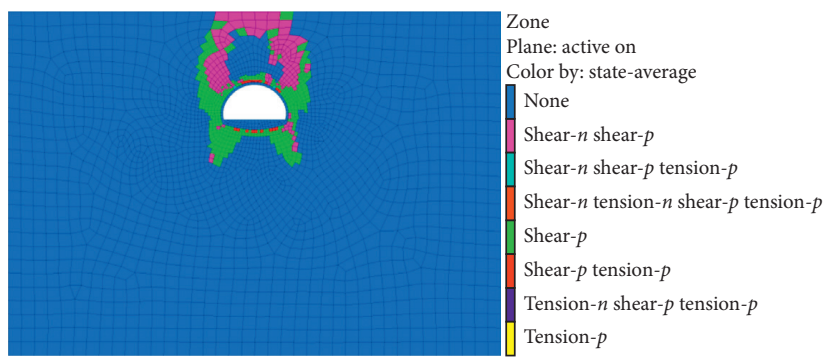

(d)

FIGURE 20: Distribution of plastic zone after excavation. (a) Upper-bench CD method. (b) CD method. (c) CRD method. (d) Both-side drift method.

Table 5: Maximum internal force of initial support.

\begin{tabular}{lcccc}
\hline \multirow{2}{*}{ Construction method } & \multicolumn{2}{c}{ Axial force } & \multicolumn{2}{c}{ Bending moment } \\
& Maximum $(\mathrm{kN})$ & Position & Maximum $(\mathrm{kN} \cdot \mathrm{m})$ & Position \\
\hline Upper-bench CD method & 2000 & Right side of vault & 105 & Right arch foot \\
CD method & 2180 & Right arch waist & 69 & Reft foot \\
CRD method & 1970 & Left arch foot & 143 & Left foot \\
Both-side drift method & 1700 & Right arch waist & 11.7 & Left foot \\
Field test & 1967 & Left arch foot & \\
\hline
\end{tabular}

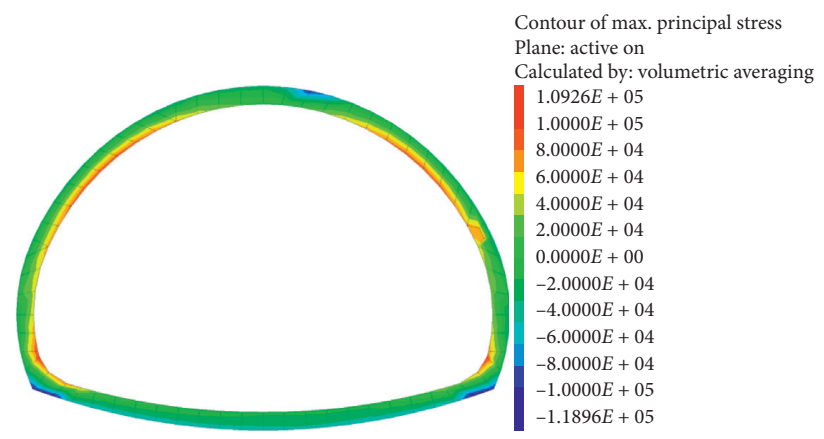

FIGURE 21: Maximum principal stress distribution of secondary lining by the upper-bench CD method.

TABLE 6: Statistics of maximum principal stresses for different construction methods.

\begin{tabular}{lcc}
\hline Construction method & Maximum tensile stress (MPa) & Maximum compressive stress (MPa) \\
\hline Upper-bench CD method & 0.109 & 0.119 \\
CD method & 0.201 & 0.15 \\
CRD method & 0.177 & 0.179 \\
Both-side drift method & 0.176 & 0.166 \\
\hline
\end{tabular}


ability of the rock mass by reducing the adverse effect of the rock mass pressure concentration on the secondary lining and enhancing the safety reserve of the secondary lining for the tunnel.

\section{Conclusions}

The main conclusions are as follows:

(1) The stress distribution of the steel frame is mainly under compression, and the maximum compressive stress of the shotcrete is located at the top of the arch. This result shows that the self-supporting ability of the steel frame and rock mass plays the main supporting role in the construction by using the upper-bench CD method, and shotcrete plays a secondary and auxiliary supporting role.

(2) Through the safety checking calculations of initial support and secondary lining, the safety factor is greater than 1.5 and 3, respectively, which shows that the existing construction technology and support parameters are feasible for shallow super large-span tunnels.

(3) Numerical simulation reveals that the influence range of the upper-bench CD method is $10 \mathrm{~m}$ distance from excavation surface, and the control of horizontal convergence and ground settlement is relatively weak. Therefore, the upper-bench CD method is suitable for tunnels with certain ground settlement.

(4) The construction efficiency and the economy are improved under the premise of satisfying the deformation of the rock mass and the safety of the structure when the upper-bench CD method is adopted. The upper-bench CD method is suitable for the shallow and underground excavation of super large-span tunnels.

\section{Data Availability}

The data used to support the findings of this study are included within the article.

\section{Conflicts of Interest}

The authors declare that they have no conflicts of interest regarding the publication of this paper.

\section{Acknowledgments}

The authors would like to acknowledge the financial support provided by the National Key R\&D Program of China (Grant no. 2018YFB1600100), the National Natural Science Fund Project of China (Grant nos. 51978065 and 51678063), the China Postdoctoral Science Foundation (Grant no. 2016M602738), and the Chang Jiang Scholars Program
(Grant no. Q2018209). These supports are gratefully acknowledged.

\section{References}

[1] P. Gwonje, J. Gukyeong, K. Taegeon, K. Jihun, K. Yongsik, and C. Yeongjin, "Research on the application of two-way four lane large section tunnel on high-speed road," Magazine of Korean Tunnelling and Underground Space Association, vol. 14, no. 4, pp. 14-24, 2017.

[2] G. Chen, B. Liu, M. Wan, Z. Hao, and W. Li, "Analysis of stress monitoring of a super large-span highway tunnel in hanjialing mountain," Journal of Rock Mechanics and Engineering, vol. 24, no. 2, pp. 5509-5515, 2005.

[3] D. Zhou, L. Cao, H. Qu, L. Yi, and S. Fang, "Deformation monitoring and control of super large section highway tunnel with different surrounding rocks," Journal of Rock Mechanics and Engineering, vol. 28, no. 12, pp. 2510-2519, 2009.

[4] Y. Luo and J. Chen, "Research status and progress of tunnel frost damage," Journal of Traffic and Transportation Engineering (English Edition), vol. 6, no. 3, pp. 297-309, 2019.

[5] L. Li, S. Sun, W. Jing et al., "Experimental study of the precursor information of the water inrush in shield tunnels due to the proximity of a water-filled cave," International Journal of Rock Mechanics and Mining Sciences, vol. 130, pp. 1-12, 2020.

[6] B. L. Li, S. Sun, J. Wang, S. Song, and M. Zhang, "Development of compound EPB shield model test system for studying the water inrushes in karst regions," Tunnelling and Underground Space Technology, vol. 101, 2020.

[7] J. Chen, W. Liu, L. Chen et al., "Failure mechanisms and modes of tunnels in monoclinic and soft-hard interbedded rocks: a case study," KSCE Journal of Civil Engineering, vol. 24, no. 4, pp. 1357-1373, 2020.

[8] W. Liu, J. Chen, L. Chen, Y. Luo, Z. Shi, and Y. Wu, "Nonlinear deformation behaviors and a new approach for the classification and prediction of large deformation in tunnel construction stage: a case study," European Journal of Environmental and Civil Engineering, pp. 1-29, 2020.

[9] S.-L. No, S.-H. Noh, S.-P. Lee, and J.-W. Seo, "Construction of long and large twin tube tunnel in Korea-Sapaesan tunnel," Tunnelling and Underground Space Technology, vol. 21, no. 34, p. 393, 2006.

[10] M. H. Sadaghiani and S. Dadizadeh, "Study on the effect of a new construction method for a large span metro underground station in tabriz-Iran," Tunnelling and Underground Space Technology, vol. 25, no. 1, pp. 63-69, 2010.

[11] M. Sharifzadeh, F. Kolivand, M. Ghorbani, and S. Yasrobi, "Design of sequential excavation method for large span urban tunnels in soft ground-niayesh tunnel," Tunnelling and Underground Space Technology, vol. 35, pp. 178-188, 2013.

[12] J. Bao, L. Yang, Y. Changxi, T. Zhicheng, and Z. Jianyang, "Construction technique of super large-span shallow-buried tunnel considering the optimal sequence of pilot-tunnel excavation," Advances in Materials Science and Engineering, vol. 2015, pp. 1-8, 2015.

[13] T. Boonyarak and C. W. W. Ng, "Effects of construction sequence and cover depth on crossing-tunnel interaction," Canadian Geotechnical Journal, vol. 52, no. 7, pp. 851-867, 2018.

[14] C. Yoo and J. Choi, "Effect of construction sequence on threearch tunnel behavior-Numerical investigation," Geomechanics and Engineering, vol. 15, no. 3, pp. 911-917, 2018. 
[15] Y. Luo, J. Chen, H. Wang, and P. Sun, "Deformation rule and mechanical characteristics of temporary support in soil tunnel constructed by sequential excavation method," KSCE Journal of Civil Engineering, vol. 21, no. 6, pp. 2439-2449, 2016.

[16] N. H. Dehnavi and M. Sadeghi, "Deterioration of weak rocks over time and its effect on designing tunnel support systems," Bulletin of Engineering Geology and the Environment, vol. 78, no. 2, pp. 1045-1056, 2017.

[17] D. Dianchun, D. Dias, N. A. Do, and P. Oreste, "Hyperstatic reaction method for the design of U-shaped tunnel supports," International Journal of Geomechanics, vol. 18, no. 6, Article ID 04018030, 2018.

[18] V. Marinos, A. Goricki, and E. Malandrakis, "Determining the principles of tunnel support based on the engineering geological behaviour types: example of a tunnel in tectonically disturbed heterogeneous rock in Serbia," Bulletin of Engineering Geology and the Environment, vol. 78, no. 4, pp. 2887-2902, 2019.

[19] Y. Luo, J. Chen, P. Huang, M. Tang, X. Qiao, and Q. Liu, "Deformation and mechanical model of temporary support sidewall in tunnel cutting partial section," Tunnelling and Underground Space Technology, vol. 61, pp. 40-49, 2017.

[20] P. Li, "Key techniques for the construction of high-speed railway large-section loess tunnels," Engineering, vol. 4, no. 2, pp. 254-259, 2018.

[21] K. F. Bizjak and B. Petkovšek, "Displacement analysis of tunnel support in soft rock around a shallow highway tunnel at Golovec," Engineering Geology, vol. 75, no. 1, pp. 89-106, 2004.

[22] T. Ito, W. Akagi, H. Shiroma, A. Nakanishi, and S. Kunimura, "Estimation of natural ground behavior ahead of face by measuring deformation which utilized tbm drift tunnel," Tunnelling and Underground Space Technology, vol. 19, pp. 527-528, 2004.

[23] W. Bjureland, J. Spross, F. Johansson, A. Prästings, and S. Larsson, "Reliability aspects of rock tunnel design with the observational method," International Journal of Rock Mechanics and Mining Sciences, vol. 98, pp. 102-110, 2017.

[24] Y. Luo, J. Chen, W. Xi et al., "Application of a total station with RDM to monitor tunnel displacement," Journal of Performance of Constructed Facilities, vol. 31, no. 4, Article ID 04017030, 2017.

[25] F. Hou, K. Sun, R. Zhao, W. Xu, Z. Zhou, and Q. Jiang, "Applicability study on construction method of super-large section neighborhood tunnel," China Civil Engineering Journal, vol. 50, no. S1, pp. 111-116, 2017.

[26] C. Xia, J. Gong, Y. Tang, and H. Zhu, "Study on site monitoring of large-section highway tunnels with small clear spacing," Journal of Rock Mechanics and Engineering, vol. 26, no. 1, pp. 44-50, 2007.

[27] D. Zhang, S. Liu, and S. Ren, "Research on selection of preliminary support for tunnel in high ground-stress soft rock based on surrounding rock-support characteristic curve theory," Journal of Rock Mechanics and Engineering, vol. 48, no. 01, pp. 139-148, 2015.

[28] M. Tang, R. Chen, and W. Chen, "Stress monitoring and internal force analysis of Guangzhou metro shield tunnel segment during construction," China Civil Engineering Journal, vol. 3, pp. 118-124, 2009.

[29] Y. Shi, J. Li, W. Li, and X. Zhou, "Construction mechanics of tunnel with super-large cross-section and its dynamic stability," Journal of Shanghai Jiaotong University, vol. 49, no. 7, pp. 1023-1029, 2015.
[30] M. Bai, Z. Xu, J. Shi, A. Zhang, J. Lei, and J. Xie, “Analysis of ground settlement of a subway station undercut with shallow overburden during construction with FLAC3D under complex geological conditions," Journal of Rock Mechanics and Engineering, china, Wuhan, vol. 25, no. S2, pp. 4254-4260, 2015. 